\title{
Harmonic Analysis of A DFIG for Wind Energy Conversion System
}

\author{
Lingling Fan, Senior Member, IEEE, Subbaraya Yuvarajan, Senior Member, IEEE, Rajesh Kavasseri, Senior \\ Member, IEEE
}

\begin{abstract}
The aim of this paper is to develop a framework for analysis of harmonics in a Doubly Fed Induction Generator (DFIG) caused by non-sinusoidal conditions in the rotor as well as unbalance in stator. Non-sinusoidal rotor voltages are decomposed into harmonic components and their corresponding sequences are identified. Then induced harmonics in rotor and stator are analyzed and computed, from which the torques produced by these interactions between stator and rotor harmonic components can be found. During unbalanced stator conditions, symmetric component theory is applied to the stator voltage to get positive-, negative and zero- sequence components of stator and rotor currents. The steady-state negative sequence equivalent circuit for a DFIG is derived based on reference frame theory. Harmonic currents in the rotor are computed based on the positive and negative sequence circuits. In both scenarios, the harmonic components of the electromagnetic torque are calculated from the interactions of the harmonic components of the stator and rotor currents. Three case studies are considered, namely, (i) non-sinusoidal rotor injection, (ii) an isolated unbalanced stator load scenario and (iii) grid-connected operation. The analysis is verified with results obtained through numerical simulations in Matlab/Simulink. The second case is verified using experiments. The simulation results and experimental results agree well with the results from analysis.
\end{abstract}

Index Terms-Wind Generation, Doubly Fed Induction Generator, Inverter, Harmonics, Unbalance

\section{NOMENCLATURE}

$\omega_{s}, \omega_{r}, \omega_{m} \quad$ Stator, rotor and rotating frequency.

$\bar{I}_{s}, \bar{I}_{r}$

Stator, rotor current vectors.

$i_{q s}, i_{d s}$

$i_{q r}^{\prime}, i_{d r}^{\prime}$

$\mathrm{q}$-axis and d-axis stator currents.

$\mathrm{q}$-axis and d-axis rotor currents

referring to the stator side.

Subscripts

$s, r \quad$ Stator, rotor.

,+- Positive, negative components.

$q, d \quad$ rotating reference frame.

\section{INTRODUCTION}

D OUBLY Fed Induction Generators (DFIGs) are widely used in wind generation. The possibility of getting a constant frequency AC output from a DFIG while driven by a variable speed prime mover improves the efficacy of energy harvest from wind [1]. Unlike a squirrel-cage induction generator, which has its rotor short circuited, a DFIG has its rotor terminals accessible. The rotor of a DFIG is fed

L. Fan, S. Yuvarajan and R. Kavasseri are with Dept. of Electrical \& Computer Engineering, North Dakota State University, Fargo, ND 58105. Email: Lingling.Fan@ndsu.edu, Subbaraya.Yuvarajan@ndsu.edu, Rajesh.Kavasseri@ndsu.edu. with a variable-frequency $\left(\omega_{r}\right)$, variable magnitude three-phase voltage. This AC voltage injected into the rotor circuit will generate a flux with a frequency $\omega_{r}$ if the rotor is standing still. When the rotor is rotating at a speed $\omega_{m}$, the net flux linkage will have a frequency $\omega_{s}=\omega_{r}+\omega_{m}$. When the wind speed changes, the rotor speed $\omega_{m}$ will change and in order to have the net flux linkage at a frequency $60 \mathrm{~Hz}$, the rotor injection frequency should also be adjusted. A key requirement of DFIG is to have its three-phase rotor circuit injected with a voltage at a controllable frequency and controllable magnitude.

The three-phase ac voltage can be synthesized using various switching techniques, including six-step switching [2], Pulse Width Modulation (PWM) [1], and space vector PWM [3]. To reduce the switching losses while having a simple control circuit, six-step switching technique is widely used in thyristor based inverter. The high power capability of thyristor attracts the implementation of thyristor based converters in wind energy system and six-step switching has kindled a new interest in wind energy system [4], [5]. Six-step switching technique generates quasi-sine ac voltages which possess $6 n \pm 1$ harmonics. Under such conditions, the rotor currents contain harmonic components which in turn induce corresponding harmonics in the stator. This leads to the pulsating torques.

Harmonics can also be introduced by unbalanced stator conditions. Unbalanced stator voltages can be resolved into positive-, negative-, and zero-sequence voltages. Negativesequence components in the stator lead to high frequency component in the rotor currents and torque [6]-[9]. Negative sequence components lead to several undesirable conditions, such as overcurrent in rotor circuits and overheating. The focus in these works is to develop control schemes to minimize overcurrents and pulsating torques.

In [6] and [9], the synchronous reference frame $q d^{+}$is used and controllers are developed to deal with $2 \omega_{e}$ frequency harmonics ( $\omega_{e}$ is the system frequency). In [7] and [10] two reference frames: the positive $\left(q d^{+}\right)$and negative $\left(q d^{-}\right)$ synchronous reference frames are used and low pass filters are used to extract positive and negative sequence components while blocking the $2 \omega_{e}$ components. The positive and negative sequence components are then controlled separately via PI controller. More recently, for generalized grid converters, $\alpha \beta$ reference frame is used and proportional resonance controller is adopted [8].

The focus of this paper is to develop a framework for analysis of harmonics in a DFIG caused by non-sinusoidal conditions in the rotor as well as unbalance in stator. Torque expression under unbalanced stator conditions are derived 
mathematically using space vector expression in [7], [9]. In this paper, the dc and pulsating components in the torque are computed from the harmonic interactions between the stator and rotor currents.

Non-sinusoidal rotor voltages are decomposed into harmonic components and their corresponding sequences are identified. Then induced harmonics in rotor and stator are analyzed and computed, from which the torques produced by these interactions between stator and rotor harmonic components can be found.

During unbalanced stator conditions, symmetric component theory is applied to the stator voltage to get positive-, negativeand zero- sequence components of stator and rotor currents. The steady-state negative sequence circuit for a DFIG is derived based on reference frame theory. Harmonic currents in the rotor are obtained based on the positive and negative sequence circuit. Harmonic components due to the interactions between stator and rotor sequence components in torque can be found.

The paper is organized as follows. Section II gives the steady-state equivalent circuit of the DFIG under positive, negative- sequence and harmonic scenarios. Section III presents the harmonic analysis of a DFIG with non-sinusoidal rotor circuit injection. Section IV presents the harmonic analysis of a DFIG under unbalanced stator condition. Three case studies, namely, (i) non-sinusoidal rotor injection, (ii) an isolated unbalanced load and (iii) grid-connected operation. are given in Section V. The analysis along with experiments and numerical simulations in Matlab/Simulink are given. Section VI concludes the paper.

\section{Steady-State Equivalent Circuit of A DFIG}

For analysis, the per-phase steady state equivalent circuit of a DFIG based on [11], [12] is shown in Fig. 1. Here $N, \omega_{s}$ and slip are defined based on sequence and harmonic conditions. For example, when $N=1, \omega_{s}=\omega_{e}$ and slip $=s$, the circuit corresponds to the well-known positive sequence equivalent circuit of an induction machine. For harmonic and negative sequence condtions, the parameters are modified and details are presented in Section III and IV respectively.

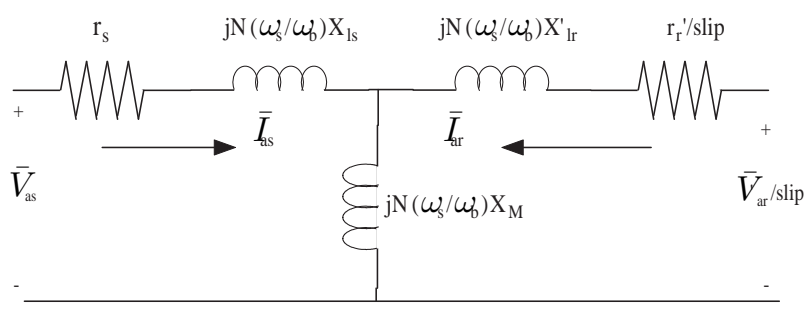

Fig. 1. Steady-state induction machine circuit representation.

Remarks:

- positive sequence circuit:

$$
\left\{\begin{array}{l}
N=1 \\
\omega_{s}=\omega_{e} \\
\text { slip }=s
\end{array}\right.
$$

- negative sequence circuit:

$$
\left\{\begin{array}{l}
N=-1, \\
\omega_{s}=-\omega_{e}, \\
\text { slip }=2-s .
\end{array}\right.
$$

- $6 n-1$ harmonic rotor injection:

$$
\left\{\begin{array}{l}
N=-1, \\
\omega_{s}=(6 n-1) \omega_{r}-\omega_{m}, \\
\text { slip }=\frac{(6 n-1) \omega_{r}}{(6 n-1) \omega_{r}-\omega_{m}} .
\end{array}\right.
$$

- $6 n+1$ harmonic rotor injection:

$$
\left\{\begin{array}{l}
N=1, \\
\omega_{s}=(6 n+1) \omega_{r}+\omega_{m}, \\
\text { slip }=\frac{(6 n+1) \omega_{r}}{(6 n-1) \omega_{r}+\omega_{m}} .
\end{array}\right.
$$

\section{HARMONIC ANALYSIS With QUASI-Sine Rotor VOLTAGE INJECTION}

In this section, harmonic analysis in the stator circuits with quasi-sine rotor voltage injection will be investigated. The injected ac voltage to the rotor usually comes from a DC/AC bridge converter shown in Fig. 2. While Pulse Width Modulation (PWM) technique is widely used for rotor injection [1], six-step switching technique is another possibility to simplify the control circuit and reduce the switching losses. Six-step switching introduces $6 n \pm 1$ harmonics in the voltages and the resultant output is called a quasi-sine waveform. Unlike PWM, this does not need sine and triangular waves. It is easy to adjust the rotor injection frequency by simply varying a control voltage. The output line voltage of the inverter is a quasi-sine wave with levels $0, V_{B}$, and $-V_{B}$ and one of the three line voltages and a phase voltage are shown in Fig. 3 .

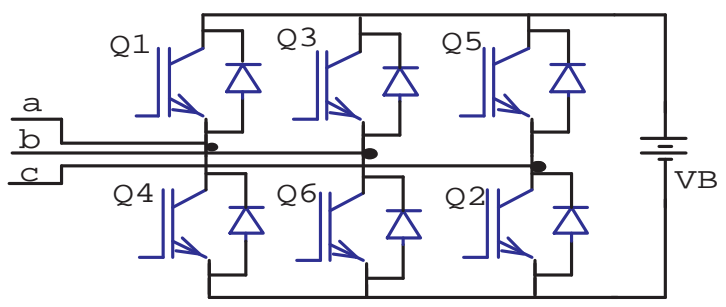

Fig. 2. Power circuit of three-phase bridge inverter.

\section{A. Harmonic Components in Stator and Rotor Currents}

For the quasi-sine waveforms of Fig. 3, triple-n harmonics $(3,6,9,15, \ldots)$ are absent. The voltage waveform in phase A can be expressed in the mathematical form as [2]:

$$
v_{r a}(t)=V_{S} \sum_{k}^{\infty} \frac{1}{k} \sin (k \omega t), k=1,5,7, \ldots
$$

where $V_{S}=\frac{2}{\pi} V_{B}$. 


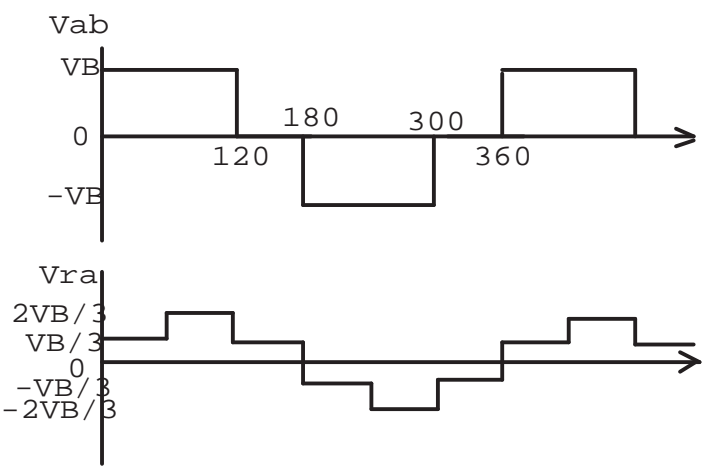

Fig. 3. Quasi-sine waveforms of line and phase voltage applied to the rotor.

The $120^{\circ}$ phase displacements among the three phase voltages can be conveniently represented as:

$$
\begin{aligned}
& v_{r a}(t)=\operatorname{Im}\left(V_{S} \sum_{k}^{\infty} \frac{1}{k} e^{j k \omega t}\right) \\
& v_{r b}(t)=\operatorname{Im}\left(V_{S} \sum_{k}^{\infty} \frac{1}{k} e^{j k \omega(t-\tau)}\right) \\
& v_{r c}(t)=\operatorname{Im}\left(V_{S} \sum_{k}^{\infty} \frac{1}{k} e^{j k \omega(t-2 \tau)}\right)
\end{aligned}
$$

where $k=1,5,7,11, \ldots$, and $\omega \tau=\frac{2 \pi}{3}$.

For the 5th and any $(6 n-1)^{t h}(n>0)$ harmonic, the waveforms of the rotor voltages are given by:

$$
\begin{aligned}
& v_{r a}(t)=\operatorname{Im}\left(V_{S} \frac{1}{6 n-1} e^{j(6 n-1) \omega t}\right) \\
& v_{r b}(t)=\operatorname{Im}\left(V_{S} \frac{1}{6 n-1} e^{j(6 n-1) \omega t} e^{j \frac{2 \pi}{3}}\right) \\
& v_{r c}(t)=\operatorname{Im}\left(V_{S} \frac{1}{6 n-1} e^{j(6 n-1) \omega t} e^{-j \frac{2 \pi}{3}}\right)
\end{aligned}
$$

Thus, the set of $(6 n-1)$ harmonics can be considered as a negative sequence set. The frequency of the waveform is equivalent to $-(6 n-1) \omega$. Through out the paper, a negative sign for the frequency implies a negative sequence for the corresponding quantity.

Using the same analogy, for the 7th or any $(6 n+1)$ harmonic, the three-phase set is considered as a positive sequence set and the frequency of the waveform is $(6 n+1) \omega$.

Therefore, the following harmonic components can be observed in the stator current: $\omega_{r}+\omega_{m},-5 \omega_{r}+\omega_{m}, 7 \omega_{r}+\omega_{m}$, $-11 \omega_{r}+\omega_{m}, 13 \omega_{r}+\omega_{m}$ and etc. The lowest order harmonic (LOH) observed is $\left|5 \omega_{r}-\omega_{m}\right|$.

The magnitudes of the harmonics in the stator current can be computed based on the steady-state equivalent circuit in Fig. 1.

\section{B. Harmonic Components and Magnitudes of Electromagnetic Torque}

The harmonic analysis of a DFIG is similar as the harmonic analysis of an induction machine presented in [2]. For induction motor with quasi-sine ac power supply, the harmonics present in stator currents and electromagnetic torque are $n \times 60$ $\mathrm{Hz}$, while in a DFIG with quasi-sine rotor injection, the harmonics in stator currents and electromagnetic torque are dependent on the injected frequencies.

The constant or steady torques are developed by the reaction of harmonic air gap fluxes with harmonic rotor mmfs, or currents, of the same order. Since the $6 n-1$ harmonics are negative-sequence harmonics, the induced torques oppose the torques produced by the fundamental mmfs and $6 n+1$ harmonics [2].

Besides the steady torques, there are also pulsating torque components, which are produced by the reaction of harmonic rotor mmfs with harmonic rotating fluxes of different order. The reaction between the fundamental rotor $\mathrm{mmf}$ and the 5th harmonic component in the stator current will cause a pulsating torque with frequency of $\omega_{r 1}+\omega_{m}-\omega_{s 5}=6 \omega_{r}$. Similarly, the reaction between the 5 th rotor mmf and the fundamental component in the stator current will produce a pulsating torque with frequency of $\omega_{r 5}+\omega_{m}-\omega_{s 1}=-6 \omega_{r}$. The reactions between the fundamental rotor $\mathrm{mmf}$ and the 7 th harmonic component in the stator current, and the 7th rotor $\mathrm{mmf}$ and the fundamental component in the stator current will produce pulsating torques of the same frequency $6 \omega_{r}$ as well.

Similarly, the interactions between the fundamental rotor mmf and the 11th (13th) harmonic component in the stator current will produce a pulsating torque with frequency of $12 \omega_{r}$. In general, the pulsating torque contains harmonics of $6 n \omega_{r}(n>0)$.

The torque can be expressed in terms of of stator and rotor currents in the same reference frame [12] or current space vector [2]. The torque in terms of the qd currents and the current space vector can be written as:

$$
\begin{aligned}
T_{e} & =\left(\frac{3}{2}\right)\left(\frac{P}{2}\right) M\left(i_{q s} i_{d r}^{\prime}-i_{d s} i_{q r}^{\prime}\right) \\
& =3\left(\frac{P}{2}\right) M \operatorname{Im}\left[\bar{I}_{s} \bar{I}_{r}^{*}\right] .
\end{aligned}
$$

where $\bar{I}_{s}=1 / \sqrt{2}\left(i_{q s}-j i_{d s}\right)$ and $\bar{I}_{r}=1 / \sqrt{2}\left(i_{q r}^{\prime}-j i_{d r}^{\prime}\right)$.

The steady torque can be expressed in current space vector as

$$
T_{e 0}=3\left(\frac{P}{2}\right) M \operatorname{Im} \sum_{k}\left[\bar{I}_{s k} \bar{I}_{r k}^{*}\right]
$$

where $k=1,5,7,9,11, \ldots, \bar{I}_{k}=1 / \sqrt{2}\left(i_{q k}-j i_{d k}\right)$. The qd variables are referred to the rotating reference frame with the same speed as the frequency of the stator harmonic component.

The pulsating torque of $6 \omega_{r}$ frequency can be expressed as:

$$
\begin{aligned}
T_{e 6} & =3\left(\frac{P}{2}\right) M \operatorname{Im}\left[\bar{I}_{s 1} \bar{I}_{r 5}^{*} e^{j 6 \omega_{r}}\right] \\
& +3\left(\frac{P}{2}\right) M \operatorname{Im}\left[\bar{I}_{s 1} \bar{I}_{r 7}^{*} e^{-j 6 \omega_{r}}\right] \\
& +3\left(\frac{P}{2}\right) M \operatorname{Im}\left[\bar{I}_{s 5} \bar{I}_{r 1}^{*} e^{-j 6 \omega_{r}}\right] \\
& +3\left(\frac{P}{2}\right) M \operatorname{Im}\left[\bar{I}_{s 7} \bar{I}_{r 1}^{*} e^{j 6 \omega_{r}}\right]
\end{aligned}
$$

$i_{q s 1}$ and $i_{d s 1}$ are in the reference frame with a rotating speed of $\omega_{s 1}, i_{q r 5}$ and $i_{d r 5}$ are in the reference frame with a rotating 
speed of $\omega_{s 5}$. And $i_{q r 7}$ and $i_{d r 7}$ are in the reference frame with a rotating speed of $\omega_{s 7}$.

The pulsating torque of $T_{e 6}$ can be expressed in real variables as

$$
T_{e 6}=T_{e \cos 6} \cos \left(6 \omega_{r} t\right)+T_{e \sin 6} \sin \left(6 \omega_{r} t\right)
$$

where $T_{e \cos 6}$ and $T_{e \sin 6}$ can be expressed by currents in (9).

\section{HARMONiC ANALYSis For Unbalanced Stator CONDITION}

The purpose of the analysis is to investigate the DFIG operation at unbalanced stator conditions and study the waveforms of the rotor currents and the electromagnetic torque. It is assumed that sinusoidal voltages are injected into the rotor and that the rotor injection voltage magnitude is constant during the system disturbance.

There are two steps in the analysis. The first step is to identify the harmonic components in the rotor currents and the electromagnetic torque and the second step is to estimate the magnitude of each harmonic component.

\section{A. Harmonic Components in Stator and Rotor Currents}

The stator frequency is assumed to be $60 \mathrm{~Hz}$. During stator unbalance, the magnitudes of the three phase voltages will not be the same. Also the phase angle displacements of the three voltages will not be $120^{\circ}$. Using symmetric component theory, any three-phase voltages can be decomposed into a positive, a negative and a zero sequence component. The stator currents will in turn have positive, negative and zero sequence components.

For an induction machine, the sum of the rotor injection frequency and the rotor frequency equals to the stator frequency or $\omega_{r}+\omega_{m}=\omega_{s}$. For the positive sequence voltage set with frequency $\omega_{s}$ applied to the stator side, the resulting rotor currents or flux linkage have a frequency $\omega_{r}=\omega_{s}-\omega_{m}=s \omega_{s}$.

The negative sequence voltage set can be seen as a threephase balanced set with a negative frequency $-\omega_{s}$. Thus the induced flux linkage in rotor circuit and the rotor currents have a frequency of $-\omega_{s}-\omega_{m}=-(2-s) \omega_{s}$.

Observed from the synchronous reference frame $q d+$ with a rotating speed $\omega_{e}$, the first component (positive sequence) has a frequency of $s \omega_{s}-\left(\omega_{e}-\omega_{m}\right)=0$, or a dc component, and the second component has a frequency of $-(2-s) \omega_{s}-$ $\left(\omega_{e}-\omega_{r}\right)=-2 \omega_{e}$, i.e., $120 \mathrm{~Hz}$. Observed from the negative synchronous reference frame $q d^{-}$which rotates clockwisely with the synchronous speed $\omega_{e}$, then the positive sequence component has a frequency of $s \omega_{s}-\left(-\omega_{e}-\omega_{m}\right)=2 \omega_{e}$, and the negative sequence component has a frequency of $-(2-s) \omega_{s}-\left(-\omega_{e}-\omega_{m}\right)=0$. The two reference frames are shown in Fig. 4 and Table I shows the components of the rotor currents in $a b c$ and the two reference frames.

The rotor currents in both reference frames will have a dc component and a high frequency component. To extract the harmonic components in the rotor currents, both a synchronous reference frame $q d^{+}$and a clockwise synchronously rotating reference frame $q d^{-}$(Fig. 4) will be used. A low pass filter with a suitable cutoff frequency can be used to extract the

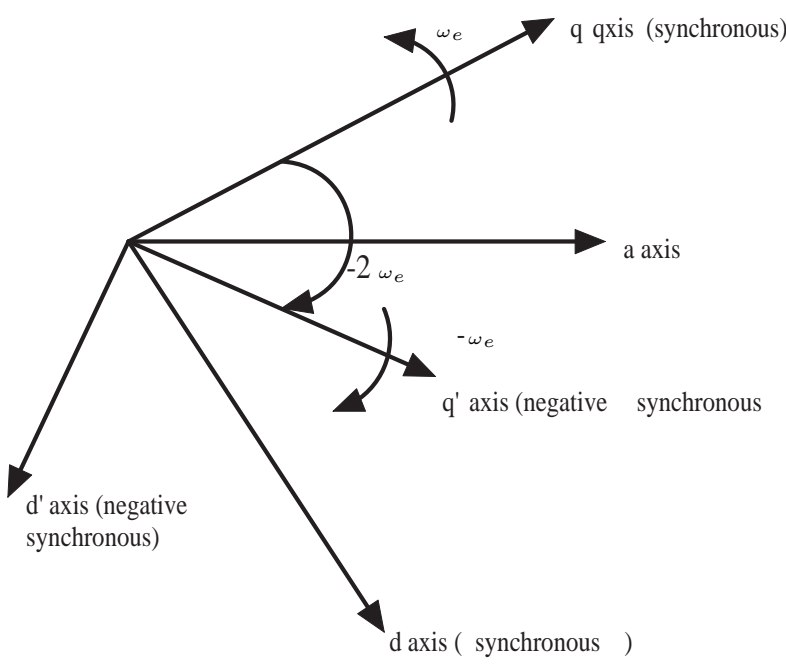

Fig. 4. The two reference frames: synchronous and negatively synchronous.

TABLE I

ROTOR CURRENT COMPONENTS OBSERVED IN VARIOUS REFERENCE FRAMES

\begin{tabular}{|c|c|c|c|}
\hline \hline & abc & $q d^{+}$ & $q d^{-}$ \\
\hline Positive & $s \omega_{e}$ & 0 & $2 \omega_{e}$ \\
Negative & $-(2-s) \omega_{e}$ & $-2 \omega_{e}$ & 0 \\
\hline \hline
\end{tabular}

dc components which correspond to the magnitudes of the two harmonic components. The scheme for extracting the $\mathrm{dc}$ components is shown in Fig. 5.

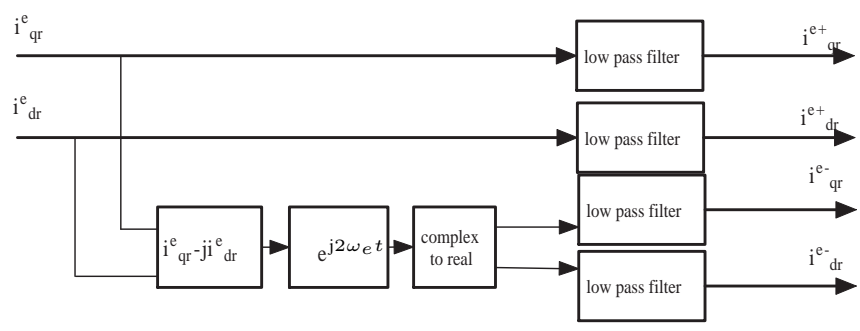

Fig. 5. Scheme for extracting dc components.

\section{B. Magnitudes of the Harmonic Components in Stator and Rotor Currents}

In this section, the derivation of the steady-state circuit for the negative sequence components is given. The equivalent circuit is derived by establishing the relationship of the voltages and currents expressed in qd variables and further in phasors.

For the negative sequence, the $\mathrm{q}$-axis, $\mathrm{d}$-axis and 0 -axis variables become dc variables at steady state when the reference frame rotates at a frequency of $-\omega_{e}$. The derivatives of the flux linkages are zero at steady state. Hence the voltage and current relationship is expressed in $q d 0$ as:

$$
\begin{aligned}
v_{q s}^{-e} & =r_{s} i_{q s}^{-e}-\omega_{e} \lambda_{d s}^{-e} \\
v_{d s}^{-e} & =r_{s} i_{d s}^{-e}+\omega_{e} \lambda_{q s}^{-e} \\
v_{q r}^{\prime-e} & =r_{r}^{\prime} i_{q r}^{\prime-e}+\left(-\omega_{e}-\omega_{r}\right) \lambda_{d r}^{\prime-e} \\
v_{d r}^{\prime-e} & =r_{r}^{\prime} i_{d r}^{\prime-e}-\left(-\omega_{e}-\omega_{r}\right) \lambda_{q r}^{\prime-e} .
\end{aligned}
$$




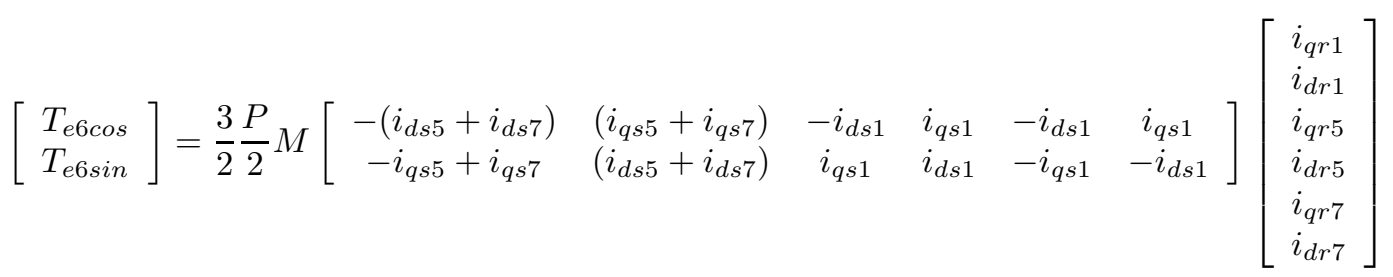

The relationship between a phasor $\tilde{F}_{a s}$ at a given frequency and the corresponding qd variables in the reference frame rotating at the same frequency can be expressed as:

$$
\sqrt{2} \tilde{F}_{a}=F_{q}-j F_{d}
$$

where $F$ can be voltages, currents or flux linkages in the stator or rotor circuits.

Therefore, the stator and rotor voltage, current, and flux linkage relationship can be expressed in phasor form as:

$$
\begin{aligned}
\tilde{V}_{a s}^{-e} & =r_{s} \tilde{I}_{a s}^{-e}-j \omega_{e} \tilde{\lambda}_{a s}^{-e} \\
\tilde{V}_{a r}^{\prime-e} & =r_{r}^{\prime} \tilde{I}_{a r}^{\prime}-j\left(\omega_{e}+\omega_{r}\right) \tilde{\lambda}_{a r}^{-e}
\end{aligned}
$$

The rotor relationship can be further expressed as

$$
\frac{\tilde{V}_{a r}^{\prime-e}}{2-s}=\frac{r_{r}^{\prime}}{2-s} \tilde{I}_{a r}^{\prime-e}-j \omega_{e} \tilde{\lambda}_{a r}^{-e} .
$$

The equivalent circuit in Fig. 1 has $N=-1, \omega_{s}=\omega_{e}$ and $\operatorname{slip}=2-s$. If the rotor voltage injection is assumed to be a balanced sinusoidal three-phase set, then the negative component $\tilde{V}_{a r}^{\prime-e}=0$.

Thus, the stator and rotor currents are induced by both the positive sequence voltages and negative sequence voltages. The rotor currents have two components, one at the low frequency $s \omega_{e}$ having a RMS magnitude of $I_{a s+}$ and the other at the high frequency $(2-s) \omega_{e}$ with a magnitude of $I_{a s-}$.

\section{Harmonic Components and Magnitudes of Electromagnetic Torque}

The zero sequence stator currents will not induce a torque [12]. Meanwhile, the 0 -axis stator circuit and 0 -axis rotor circuit are completely decoupled. Hence the 0 -axis variable transformed from stator side will not induce any voltage at rotor side. In most machines, wye connection is used so even the stator side will have no zero sequence currents.

Under unbalanced stator condition, the stator current has two components: positive sequence $\bar{I}_{s+}$ and negative sequence components $\bar{I}_{s-}$. The rotor current also has two components: positive sequence $\bar{I}_{r+}$ and negative sequence components $\bar{I}_{r-}$. The electromagnetic torque is produced by the interactions between the stator and rotor currents. The torque can be decomposed into four components:

$$
T_{e}=T_{e 1}+T_{e 2}+T_{e 3}+T_{e 4}
$$

where $T_{e 1}$ is due to the interaction of $\bar{I}_{s+}$ and $\bar{I}_{r+}, T_{e 2}$ is due to the interaction of $\bar{I}_{s-}$ and $\bar{I}_{r-}, T_{e 3}$ is due to the interaction of $\bar{I}_{s+}$ and $\bar{I}_{r-}$, and $T_{e 4}$ is due to the interaction of $\bar{I}_{s-}$ and $\bar{I}_{r+}$.

It will be convenient to use both the synchronously rotating reference frame and the negative synchronous reference frame to compute $T_{e}$. For example, $T_{e 1}$ can be identified as a dc variable in synchronous reference frame. $T_{e 2}$ can be identified as a dc variable in negative synchronous reference frame. $T_{e 3}$ and $T_{e 4}$ are pulsating torques with a frequency $2 \omega_{e}$. The expressions for the torque components are as follows:

$$
\begin{aligned}
T_{e 1} & =3\left(\frac{P}{2}\right) M \operatorname{Im}\left[\bar{I}_{s+}^{e} \bar{I}_{r+}^{* e}\right] \\
T_{e 2} & =3\left(\frac{P}{2}\right) M \operatorname{Im}\left[\bar{I}_{s-}^{-e} \bar{I}_{r-}^{*-e}\right] \\
T_{e 3} & =3\left(\frac{P}{2}\right) M \operatorname{Im}\left[\bar{I}_{s+}^{e} \bar{I}_{r-}^{* e}\right] \\
& =3\left(\frac{P}{2}\right) M \operatorname{Im}\left[\bar{I}_{s+}^{e} \bar{I}_{r-}^{*-e} e^{j 2 \omega_{e} t}\right] \\
T_{e 4} & =3\left(\frac{P}{2}\right) M \operatorname{Im}\left[\bar{I}_{s-}^{e} \bar{I}_{r+}^{* e}\right] \\
& =3\left(\frac{P}{2}\right) M \operatorname{Im}\left[\bar{I}_{s-e}^{-e} \bar{I}_{r+}^{* e} e^{-j 2 \omega_{e} t}\right]
\end{aligned}
$$

where $\bar{I}_{s}=1 / \sqrt{2}\left(i_{q s}-j i_{d s}\right)$ and $\bar{I}_{r}^{\prime}=1 / \sqrt{2}\left(i_{q r}^{\prime}-j i_{d r}^{\prime}\right)$, and $F_{+}^{e}$ is the qd variables of the positive sequence component in synchronous reference frame; $F_{-}^{e}$ is the qd variables of the negative sequence component in synchronous reference frame; $F_{+}^{-e}$ is the qd variables of the positive sequence component in negative synchronous reference frame; $F_{-}^{-e}$ is the qd variables of the positive sequence component in negative synchronous reference frame.

The torque expression under unbalanced stator condition is

$$
T_{e}=T_{e 0}+T_{e \sin 2} \cdot \sin \left(2 \omega_{s} t\right)+T_{e \cos 2} \cdot \cos \left(2 \omega_{s} t\right) .
$$

where the expression of $T_{e 0}, T_{e s i n 2}$ and $T_{e \cos 2}$ can be found in (26).

The harmonic components in the torque can be computed from positive and negative stator/ rotor currents. In the following subsections, case studies will be performed.

\section{Case Studies - Analysis and Simulation}

\section{A. Case Study 1- Non-sinusoidal Rotor Injection}

A 4-pole 5 HP DFIG with parameters in Appendix Table VII is considered. The stator is connected to a wye connected resistive load with $22 \mathrm{Ohm}$ in each phase. The configuration of the system is shown in Fig. 6. The injected rotor voltages are quasi-sine.

The fundamental frequency of the rotor injection is 24 $\mathrm{Hz}$. The rotating speed is $1080 \mathrm{rpm}$ for the 4-pole $5 \mathrm{HP}$ DFIG. The corresponding electrical frequency is $36 \mathrm{~Hz}$. The harmonic orders of the rotor and stator currents are computed and listed in Table II. The simulation (Matlab/Simulink) 


$$
\left[\begin{array}{c}
T_{e 0} \\
T_{e s i n 2} \\
T_{e c o s 2}
\end{array}\right]=\frac{3 P M}{4}\left[\begin{array}{cccc}
i_{q s+}^{e} & -i_{d s+}^{e} & i_{q s-}^{-e} & -i_{d s-}^{-e} \\
i_{d s-}^{-e} & i_{q s-}^{-e} & -i_{d s+}^{e} & -i_{q s+}^{e} \\
i_{q s-}^{-e} & -i_{d s-}^{-e} & i_{q s+}^{e} & -i_{d s+}^{e}
\end{array}\right]\left[\begin{array}{c}
i_{d r+}^{\prime e} \\
i_{q r+}^{\prime e} \\
i_{d r-e}^{\prime-e} \\
i_{q r-}^{\prime-e}
\end{array}\right]
$$

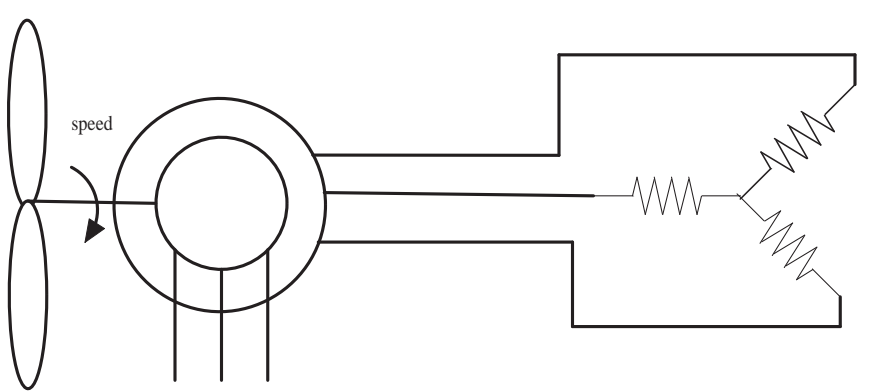

Fig. 6. A stand alone wind energy system configuration.

results are shown in Fig. 7. The 5th harmonic causes a low harmonic in stator current at $84 \mathrm{~Hz}$ of negative sequence $(24 \times 5-36)$. Hence, distortions are observed in the stator current waveforms. The torque is shown to have a steady-state dc value and a pulsating component of $144 \mathrm{~Hz}$. The FFT of the simulated electromagnetic torque, stator and rotor current waveforms are shown in Fig. 8. The FFT results show that the torque has a $144 \mathrm{~Hz}$ harmonic, the stator current has a fundamental component at $60 \mathrm{~Hz}$ and a harmonic at about 84 $\mathrm{Hz}$, and the rotor current has a fundamental component at 24 $\mathrm{Hz}$ and harmonics at 120 and $168 \mathrm{~Hz}$. The FFT results agree with the analytical results in Table II well.

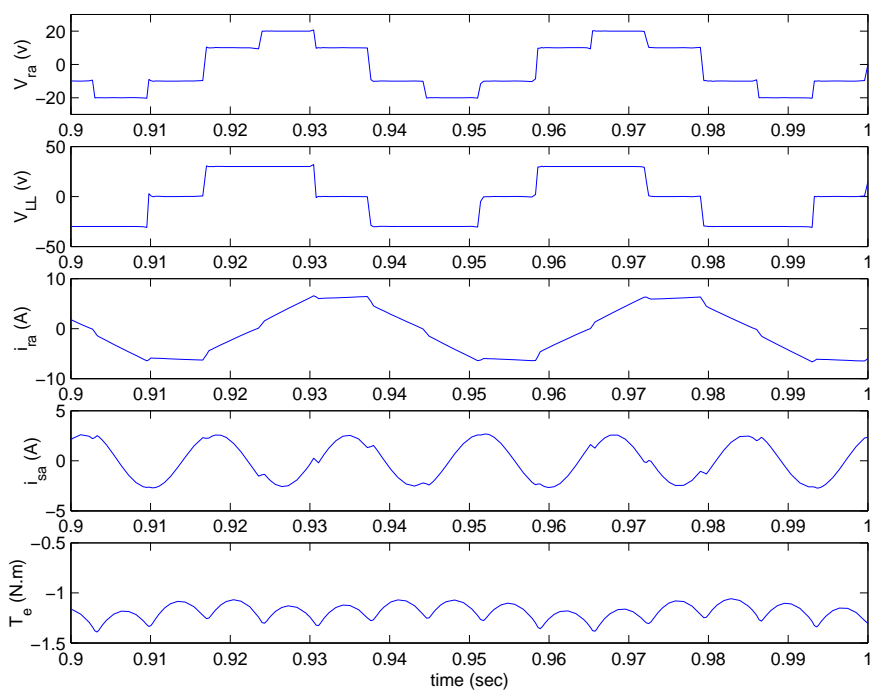

Fig. 7. A DFIG with quasi-sine rotor injection. a) phase A rotor voltage, b)phase to phase rotor voltage, c)phase A rotor current, d) phase A stator current, e) electromagnetic torque.

The $144 \mathrm{~Hz}$ pulsating torque component is produced by the reaction of harmonic rotor $\mathrm{mmfs}$ with harmonic rotating fluxes of a different order. In this case study, the 5th harmonic component causes $84 \mathrm{~Hz}$ harmonic with negative sequence in the stator current. The reaction between the fundamental
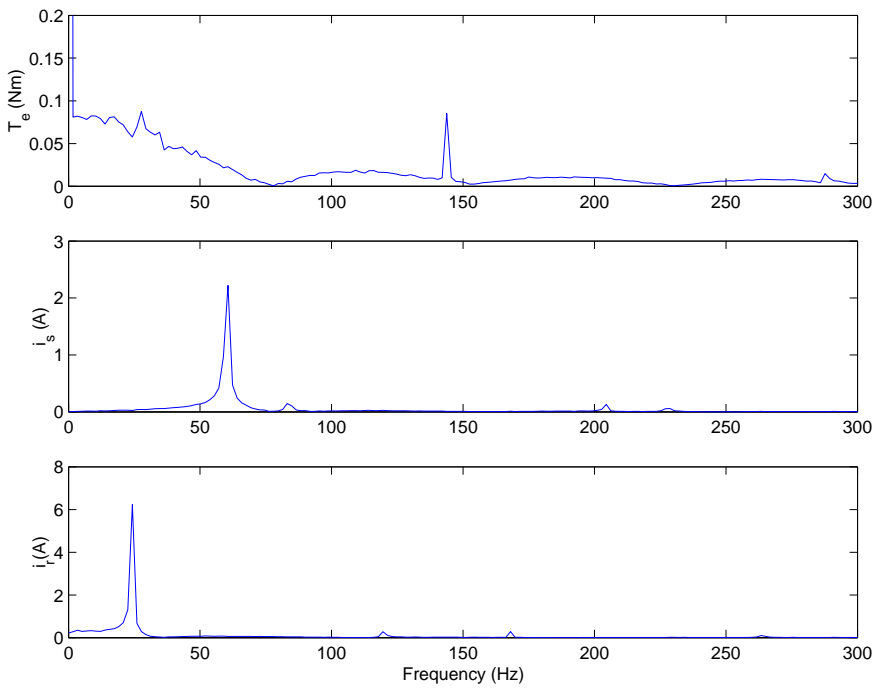

Fig. 8. FFT of the electromagnetic torque, stator and rotor current waveforms in Fig. 7.

TABLE II

ANALYZED HARMONIC COMPONENTS IN THE ROTOR AND STATOR CURRENTS DUE TO NON-SINUSOIDAL ROTOR INJECTION

\begin{tabular}{|c|c|c|c|c|c|}
\hline \hline $\begin{array}{c}\text { Harmonic } \\
\text { order }\end{array}$ & $\begin{array}{c}\text { Rotor } \\
\text { freq (Hz) }\end{array}$ & $\begin{array}{c}\text { Rotor } \\
\text { mag (A) }\end{array}$ & $\begin{array}{c}\text { Stator } \\
\text { freq }(\mathrm{Hz})\end{array}$ & $\begin{array}{c}\text { Stator } \\
\text { mag (A) }\end{array}$ & $\begin{array}{c}\text { Rotating } \\
\text { freq }(\mathrm{Hz})\end{array}$ \\
\hline $1^{\text {st }}$ & 24 & 6.52 & 60 & 2.59 & 36 \\
$5^{\text {th }}$ & -120 & 0.31 & -84 & 0.15 & 36 \\
$7^{\text {th }}$ & 168 & 0.28 & 204 & 0.18 & 36 \\
$11^{\text {th }}$ & -264 & 0.13 & -228 & 0.08 & 36 \\
\hline \hline
\end{tabular}

rotor $\mathrm{mmf}(24 \mathrm{~Hz})$ and the 5th harmonic component in the stator current $(-84 \mathrm{~Hz})$ will cause a pulsating torque of $f_{r 1}+f_{m}-f_{s 5}=144 \mathrm{~Hz}$. Similarly, the reaction between the 5 th rotor $\mathrm{mmf}(120 \mathrm{~Hz}$ negative sequence $)$ and the fundamental component in the stator current $(60 \mathrm{~Hz})$ will produce a pulsating torque of $f_{r 5}+f_{m}-f_{s 1}=-144 \mathrm{~Hz}$. The reactions between the fundamental rotor $\mathrm{mmf}$ and the 7 th harmonic component in the stator current, and the 7th rotor mmf and the fundamental component in the stator current will produce pulsating torques of $\mp 144 \mathrm{~Hz}$ as well. The dc component and the pulsating component of the torque can be computed from (7) and (9), shown in Table III. The results agree with the simulation results in Fig. 7 and the FFT results in Fig. 8.

TABLE III

HARMONIC COMPONENTS IN THE ELECTROMAGNETIC TORQUE FROM ANALYSIS

\begin{tabular}{|c|c|}
\hline \hline$T_{e 0}$ & $-1.1868 \mathrm{~N} . \mathrm{m}$ \\
$T_{e \cos 6}$ & $-0.1261 \mathrm{~N} . \mathrm{m}$ \\
$T_{e s i n} 6$ & $-0.0249 \mathrm{~N} . \mathrm{m}$ \\
$\sqrt{T_{\text {ecos } 6}^{2}+T_{\text {esin } 6}^{2}}$ & $0.1285 \mathrm{~N} . \mathrm{m}$ \\
\hline \hline
\end{tabular}


Experimental results of stator and rotor currents can be found in [13].

\section{B. Case Study 2 - A stand alone DFIG system}

In the second case study, the same setup is used except that the resistance in phase $\mathrm{A}$ is varied to create an unbalanced stator condition. The rotor injection is assumed to be balanced sinusoidal. Two scenarios will be considered. In Scenario 1, the frequency of the injected rotor voltages is $20 \mathrm{~Hz}$. In Scenario 2, the frequency of the injector rotor voltages is 15 $\mathrm{Hz}$.

In the experiment, the wind turbine is replaced by a dc motor and a 5HP wound rotor induction generator is used as a DFIG. A sine wave power source provides the injection voltage at any desired frequency. The speed of the dc motor is adjusted to have a $60 \mathrm{~Hz}$ stator voltage. The experimental setup is shown in Fig. 9.

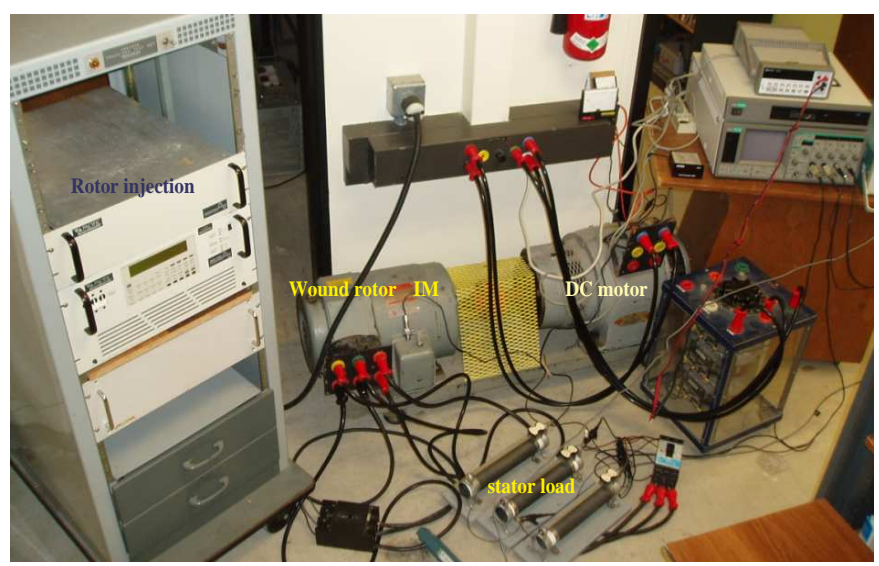

Fig. 9. Experimental setup case study 2

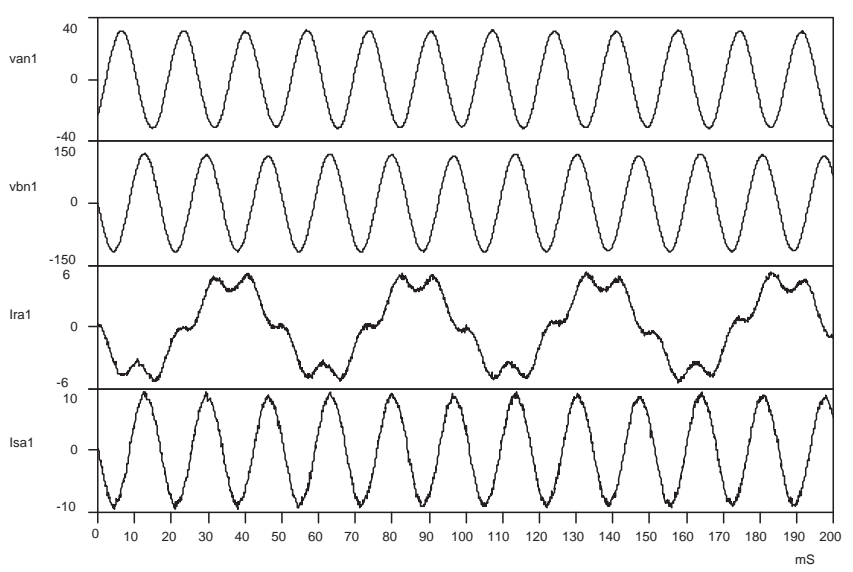

Fig. 10. Stator voltages, rotor current, and stator current under unbalanced load condition. Rotor injection frequency $=20 \mathrm{~Hz}$

Figs. 10 and 11 show the waveforms of phase A and phase B stator voltages, phase A rotor current and stator current. The experiment was conducted for two injection frequencies - $20 \mathrm{~Hz}, 15 \mathrm{~Hz}$. In both cases, the rotor current contains

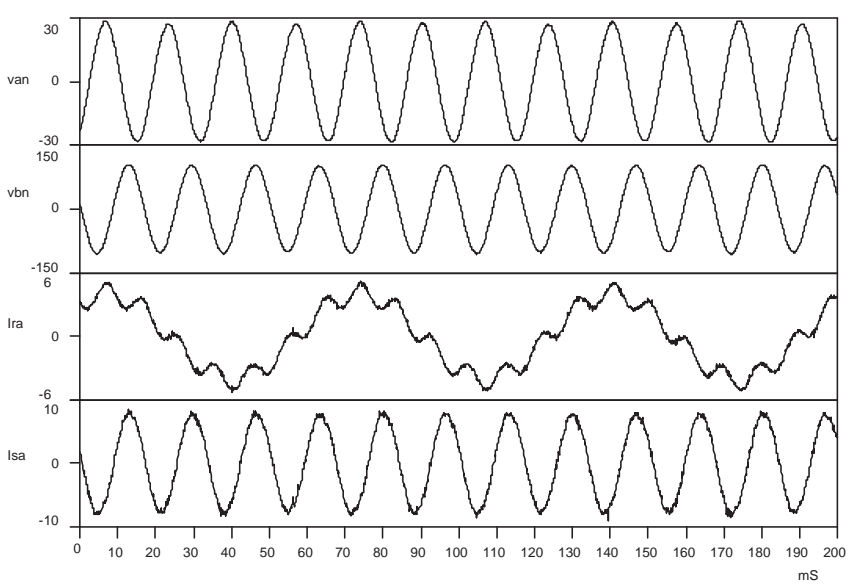

Fig. 11. Stator voltages, rotor current, and stator current under unbalanced load condition. Rotor injection frequency $=15 \mathrm{~Hz}$
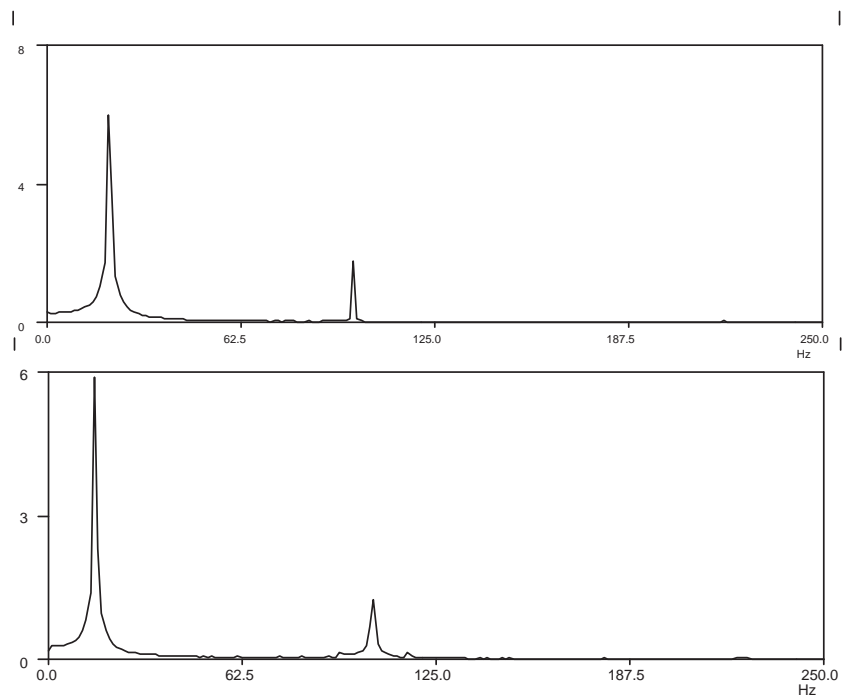

Fig. 12. FFT of the rotor currents. a) rotor injection frequency $=20 \mathrm{~Hz}$; b) rotor injection frequency $=15 \mathrm{~Hz}$.

high frequency harmonics. The results of FFT analysis of the waveforms are given in Fig. 12 and Table IV.

Unbalanced load condition due to phase A variation is equivalent to short circuiting a portion of the load in phase $\mathrm{A}$ and hence the equivalent circuit under single phase to ground fault can be used to obtain the stator current, rotor current phasors of positive sequence and negative sequence. Since the load is wye connected, there is no zero sequence current. The equivalent circuit is shown in Fig. 13.

An analysis of the circuit in Fig. 13 gives the harmonic components in the rotor currents. The phasors and the corresponding harmonic components are shown in Table IV. The experimental waveforms and the FFT analysis results agree well with the analysis results.

\section{Case Study 3-A DFIG connected to grid}

A 3 HP DFIG is used for analysis and simulation. The machine parameters are shown in Appendix. The initial condition 


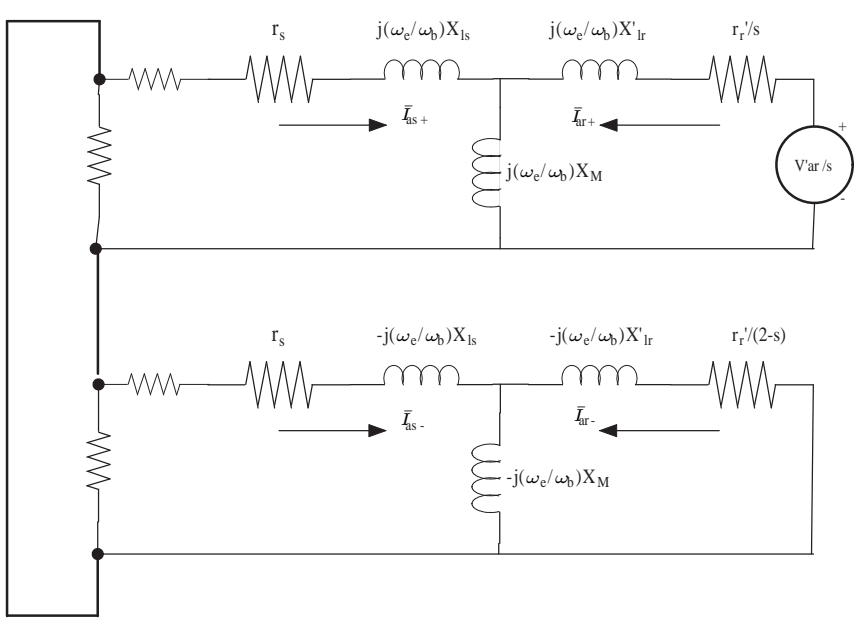

Fig. 13. Equivalent circuit for the DFIG under unbalanced stator load condition.

TABLE IV

COMPONENTS OF ROTOR CURRENTS FROM EXPERIMENTS AND ANALYSIS OF FIG. 13 DURING UNBALANCED STATOR CONDITION

\begin{tabular}{|c|c|cc|cc|}
\hline \hline & & positive & sequence & negative & sequence \\
\cline { 3 - 6 } & & experiment & analysis & experiment & analysis \\
\hline Scenario 1 & Freq & $20 \mathrm{~Hz}$ & $20 \mathrm{~Hz}$ & $98.8 \mathrm{~Hz}$ & $100 \mathrm{~Hz}$ \\
& Amp & $5.905 \mathrm{~A}$ & $5.9 \mathrm{~A}$ & $1.7175 \mathrm{~A}$ & $1.9 \mathrm{~A}$ \\
\hline Scenario 2 & Freq & $14.7 \mathrm{~Hz}$ & $15 \mathrm{~Hz}$ & $105 \mathrm{~Hz}$ & $105 \mathrm{~Hz}$ \\
& Amp & $5.743 \mathrm{~A}$ & $5.7 \mathrm{~A}$ & $1.2475 \mathrm{~A}$ & $1.26 \mathrm{~A}$ \\
\hline \hline
\end{tabular}

of the machine is the stalling state. A balanced three-phase voltage and a mechanical torque $10 \mathrm{Nm}$ are applied to the stator at $t=0$ second. The system configuration is shown in Fig. 14. At $t=1$ second, the voltage of phase A drops to zero. The fault is cleared at $t=1.5$ second. The simulation is performed in Matlab/Simulink and the results are shown in Figs. 15 - 17.

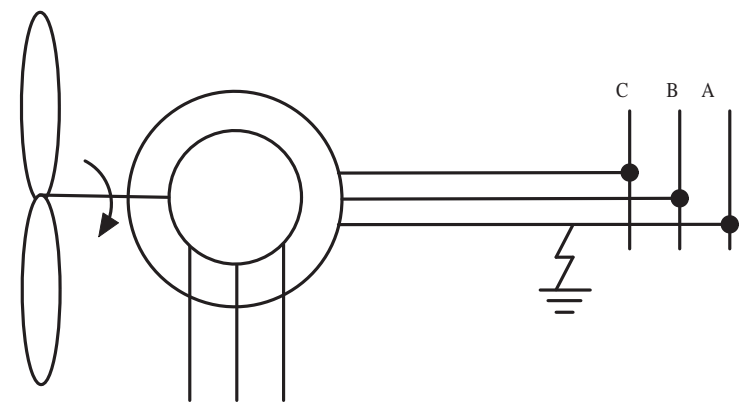

Fig. 14. A grid-interconnected DFIG system configuration.

Fig. 15 shows the dynamic responses of the rotor speed, electromagnetic torque, and stator and rotor currents in phase A. Fig. 16 shows the dynamic responses of the rotor currents in the synchronous reference frame and the negative synchronous reference frame. At the steady state balanced stator condition, the rotor speed is equivalent to $57.2 \mathrm{~Hz}$ while the slip frequency of the rotor currents is $2.8 \mathrm{~Hz}$. The two add up to $60 \mathrm{~Hz}$. During unbalance, it is found that the torque has a $120 \mathrm{~Hz}$ pulsating component. It is seen from the simulation plots that the rotor current consists of two components: a
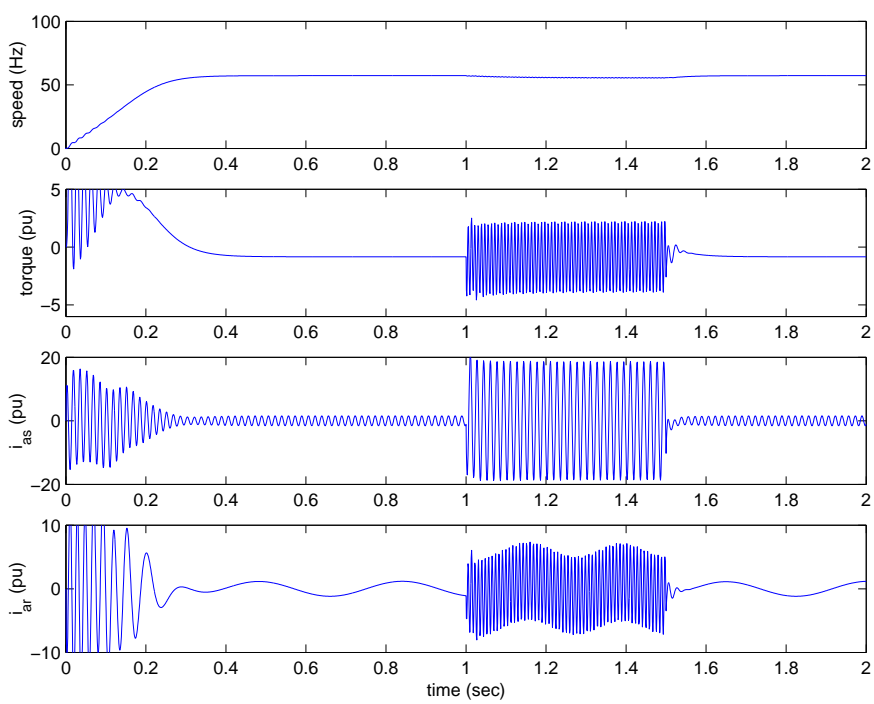

Fig. 15. Dynamic responses of rotor speed, electromagnetic torque, phase a stator current, and phase a rotor current.
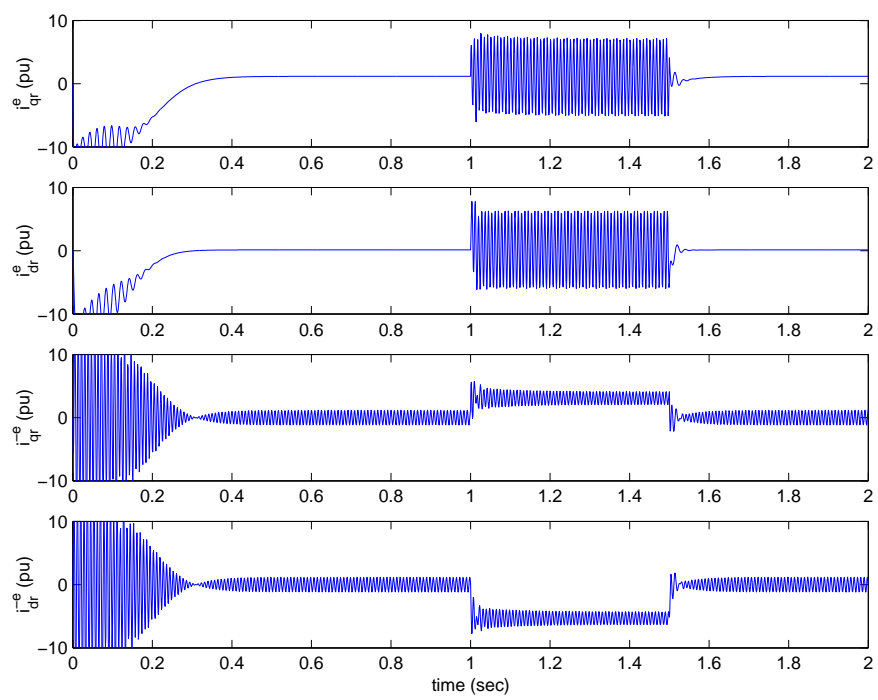

Fig. 16. Dynamic response of $i_{q r}^{e}, i_{d r}^{e}, i_{q r}^{-e}$, and $i_{d r}^{-e}$.

low frequency component and a high frequency component. According to the analysis the two frequencies are the slip frequency and a frequency close to $120 \mathrm{~Hz}\left((2-s) \omega_{e}\right)$. The rotor currents observed in the synchronous reference frame have a dc component and a $120 \mathrm{~Hz}$ component.

The magnitudes of the harmonic components can be computed from the equivalent phasor circuits in Fig. 1. Table $\mathrm{V}$ lists the calculated positive, negative, and zero sequence components in the stator voltage, stator current and rotor current.

TABLE V

CALCULATED SEQUENCE COMPONENTS IN STATOR VOLTAGES, STATOR CURRENTS AND ROTOR CURRENTS ASSUMING SLIP $=0.12$

\begin{tabular}{|c|c|c|c|c|c|c|}
\hline \hline voltage & mag & current & mag & current & mag & frequency \\
\hline$\left|V_{s}^{+}\right|$ & $88.53 \mathrm{~V}$ & $\left|I_{s}^{+}\right|$ & $4.78 \mathrm{~A}$ & $\left|I_{r}^{+}\right|$ & $4.16 \mathrm{~A}$ & $s \omega_{e}$ \\
$\left|V_{s}^{-}\right|$ & $44.26 \mathrm{~V}$ & $\left|I_{s}^{-}\right|$ & $25.87 \mathrm{~A}$ & $\left|I_{r}^{-}\right|$ & $25.14 \mathrm{~A}$ & $(2-s) \omega_{e}$ \\
$\left|V_{s}^{o}\right|$ & $44.26 \mathrm{~V}$ & $\left|I_{s}^{o}\right|$ & $50.85 \mathrm{~A}$ & $\left|I_{r}^{o}\right|$ & $0 \mathrm{~A}$ & 0 \\
\hline \hline
\end{tabular}



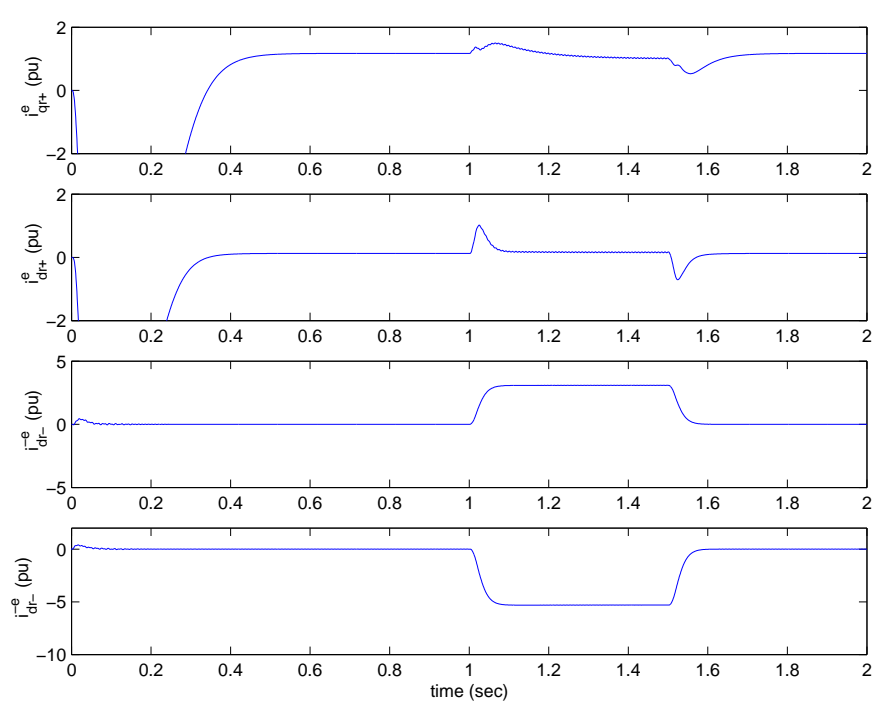

Fig. 17. Harmonic components after extracting strategy from Fig. 5, Section IV. a) $i_{q r+}^{e}-\mathrm{dc}$ component of $i_{q r}$ observed in the synchronously rotating reference frame, b) $i_{d r+}^{e}-$ dc component of $i_{d r}$ observed in the synchronously rotating reference frame, c) $i_{q r-}^{-e}-$ dc component of $i_{q r}$ observed in the negatively synchronously rotating reference frame, d) $i_{d r-}^{-e}-\mathrm{dc}$ component of $i_{d r}$ observed in the synchronously rotating reference frame..

The sequence components of the stator voltage, the stator currents and the rotor currents are listed in Table V. A comparison of the analysis results from the circuit in Fig. 1 and simulation results shows that the rotor current and torque components from analysis agree with the simulation results in Table VI.

TABLE VI

HARMONIC COMPONENTS IN THE ROTOR CURRENTS AND THE ELECTROMAGNETIC TORQUE FROM SIMULATION AND ANALYSIS DURING UNBALANCED CONDITION $($ SLIP $=4.5 / 60)$

\begin{tabular}{|c|c|c|}
\hline \hline & Simulation & Analysis \\
\hline$i_{q r+}^{e}$ & $6 \mathrm{~A}$ & $5.8 \mathrm{~A}$ \\
$i_{d r+}^{e}$ & $0.9 \mathrm{~A}$ & $0.94 \mathrm{~A}$ \\
$\mid I_{r+\mid}^{e}$ & $4.29 \mathrm{~A}$ & $4.16 \mathrm{~A}$ \\
\hline$i_{q r-}^{-e}$ & $17.9 \mathrm{~A}$ & $17.8 \mathrm{~A}$ \\
$i_{d r-}^{-e}$ & $-30.8 \mathrm{~A}$ & $-30.8 \mathrm{~A}$ \\
$\mid I_{r-1}$ & $25.2 \mathrm{~A}$ & $25.15 \mathrm{~A}$ \\
\hline$T_{e 0}$ & $-10 \mathrm{~N} . \mathrm{m}$ & $-9.89 \mathrm{~N} . \mathrm{m}$ \\
$\sqrt{T_{\text {esin } 2}^{2}+T_{e \cos 2}^{2}}$ & $35 \mathrm{~N} \cdot \mathrm{m}$ & $36.3 \mathrm{~N} . \mathrm{m}$ \\
\hline \hline
\end{tabular}

\section{CONCLUSION}

This paper presents a method to analyze harmonics caused by non-sinusoidal rotor injection and unbalanced stator conditions in a doubly-fed induction generator. Non-sinusoidal rotor voltages are decomposed into harmonic components and their corresponding sequences are identified. Then induced harmonics in rotor and stator are analyzed and computed, from which the torques produced by these interactions between stator and rotor harmonic components can be found. With unbalanced stator condition, symmetric component theory is applied and the steady-state negative sequence circuits for a DFIG is derived based on reference frame theory. Harmonic currents in the rotor are obtained based on the positive and negative sequence circuit. In both scenarios, the electromagnetic torques due to the interaction of the stator and rotor currents are explained physically and rigorous mathematic expression is derived. Three case studies considered demonstrate the proposed method in analyzing the harmonics. The proposed method is useful to analyze the effect of harmonics and unbalanced operation of DFIGs.

\section{APPENDIX}

The 3HP induction machine parameters are from [12] listed in Table VII. The 5 HP wound rotor induction machine parameters are measured from experiments and also listed in the table.

TABLE VII

MACHINE PARAMETERS FOR 3HP AND 5 HP DFIGS

\begin{tabular}{|c|c||c|c|}
\hline \hline $3 \mathrm{HP}$ & & $5 \mathrm{HP}$ & \\
\hline$R_{s}(\Omega)$ & 0.435 & $R_{s}(\Omega)$ & 0.32 \\
$X_{l s}(\Omega)$ & 0.754 & $L_{l s}(\mathrm{mH})$ & 1.19 \\
$X_{M}(\Omega)$ & 26.13 & $M(\mathrm{mH})$ & 39.46 \\
$X_{l r}^{\prime}(\Omega)$ & 0.754 & $L_{l r}(\mathrm{mH})$ & 1.34 \\
$r_{r}^{\prime}(\Omega)$ & 0.816 & $r_{r}(\Omega)$ & 0.36 \\
$J\left(k g . m^{2}\right)$ & 0.089 & turn ratio a & 1.38 \\
$T_{B}(\mathrm{~N} . \mathrm{m})$ & 11.9 & resistive load $(\Omega)$ & 22 \\
$I_{B}(\mathrm{~A})$ & 5.8 & & \\
\hline \hline
\end{tabular}

\section{REFERENCES}

[1] S. Muller, M. Deicke, and R. W. D. Doncker, "Doubly fed induction generator systems for wind turbine," IEEE Ind. Appl. Mag., pp. 26-33, May/June 2002.

[2] J. Murphy and F. Turnbull, Power Electronics Control of AC Motors. Pergamon Press, 1988.

[3] N. Mohan, First Course on Power Electronics. MNPERE Prentice Hall, 2005.

[4] P. Tenca, A. A. Rockhill, and T. A. Lipo, "Wind turbine current-source converter providing reactive power control and reduced harmonics," IEEE Trans. Ind. Appl., vol. 43, no. 4, pp. 1050-1060, July/August 2007.

[5] P. Tenca, A. A. Rockhill, T. A. Lipo, and P. Tricoli, "Current source topology for wind turbines with decreased mains current harmonics, further reducible via functional minimization," vol. 23, no. 3, pp. 11431155, May 2008.

[6] T. K. A. Brekken and N. Mohan, "Control of a doubly fed induction wind generator under unbalanced grid voltage conditions," IEEE Trans. Energy Convers., vol. 22, pp. 129-135, March 2007.

[7] L. Xu and Y. Wang, "Dynamic modeling and control of DFIG-based wind turbines under unbalanced network conditions," IEEE Trans. Power Syst., vol. 22, no. 1, pp. 314-323, February 2007.

[8] J. Hu and Y. He, "Modeling and control of grid-connected voltagesourced converters under generalized unbalanced operation conditions," IEEE Trans. Energy Convers., vol. 23, no. 3, pp. 903-913, Sep. 2008.

[9] — - "Modeling and enhanced control of DFIG under unbalanced grid voltage conditions," Eletric Power Systems Research, 2008, doi:10.1016/j.epsr.2008.06.017.

[10] R. Pena, R. Cardenas, and E. Escobar, "Control system for unbalanced operation of stand-alone doubly fed induction generators," IEEE Trans. Energy Convers., vol. 22, no. 2, 2007.

[11] A. Fitzgerald, C. Kingsley, and A. Kusko, Electric Machinery. McGraw-Hill Book Company, 1971.

[12] P. Krause, Analysis of Electric Machinery. New York: McGraw-Hill, 1986.

[13] S. Yuvarajan and L. Fan, "A DFIG-based wind generation system with quasi-sine rotor injection," Journal of Power Sources, vol. 184, no. 1, Sep. 2008. 
Lingling Fan is an assistant professor in Dept. of Electrical \& Computer Engineering, North Dakota State University. She received the BS, MS degrees in electrical engineering from Southeast University, Nanjing, China, in 1994 and 1997, respectively. She received $\mathrm{Ph} . \mathrm{D}$. degree in electrical engineering from West Virginia University in 2001. Before joining NDSU, Dr. Fan was with Midwest ISO, St. Paul, Minnesota. Her research interests include modeling and control of renewable energy systems, power system reliability and economics.

Subbaraya Yuvarajan received his Ph.D. degree in Electrical Engineering from Indian Institute of Technology, Chennai, India in 1981. He received his M. Tech degree from Indian Institute of Technology in 1969 and B.E (Hons) degree from University of Madras in 1966. Dr. Yuvarajan has been a Professor of Electrical and Computer Engineering at NDSU from 1995. His research areas are Electronics, Power Electronics and Electrical Machines.

Rajesh Kavasseri received his Ph.D. degree in Electrical Engineering from Washington State University, Pullman, WA in 2002. He is currently an associate professor in North Dakota State University. Dr. Kavasseri's research areas are power system dynamics and control, nonlinear system, algebraic geometry application in power system analysis. 